\title{
A Bayesian Decision-Support Tool for Child Sexual Abuse Assessment and Investigation
}

\section{Tadei, Alessandro}

2019-06

Tadei , A , Pensar , J , Corander , J , Finnilä , K, Santtila , P \& Antfolk , J 2019 , ' A

Bayesian Decision-Support Tool for Child Sexual Abuse Assessment and Investigation ',

Sexual Abuse, vol. 31 , no. 4 , pp. 374-396 . https://doi.org/10.1177/1079063217732791

http://hdl.handle.net/10138/240786

https://doi.org/10.1177/1079063217732791

unspecified

acceptedVersion

Downloaded from Helda, University of Helsinki institutional repository.

This is an electronic reprint of the original article.

This reprint may differ from the original in pagination and typographic detail.

Please cite the original version. 
$11{ }^{1}$ Department of Psychology and Logopedics, Åbo Akademi University, Turku, Finland

$12{ }^{2}$ Department of Mathematics and Statistics, University of Helsinki, Helsinki, Finland

$13{ }^{3}$ Department of Biostatistics, University of Oslo, Oslo, Norway.

14

15

16

17

18

$19 *$ Corresponding author

Alessandro Tadei, E-mail: atadei@abo.fi. Address: Fabriksgatan 2, 20500, Turku, Finland. 
Abstract

23 In assessments of child sexual abuse (CSA) allegations, informative background information

24 is often overlooked or not used properly. We therefore created and tested an instrument that

25 uses accessible background information to calculate the probability of a child being a CSA

26 victim that can be used as a starting point in the following investigation. Studying 903

27 demographic and socio-economic variables from over 11,000 Finnish children, we identified

2842 features related to CSA. Using Bayesian logic to calculate the probability of abuse, our

29 instrument - the Finnish Investigative Instrument of Child Sexual Abuse (FICSA) - has two

30 separate profiles for boys and girls. A cross-validation procedure suggested excellent

31 diagnostic utility ( $A U C=.97$ for boys and $A U C=.88$ for girls). We conclude that the

32 presented method can be useful in forensic assessments of CSA allegations by adding a

33 reliable statistical approach to considering background information, and to support clinical

34 decision making and guide investigative efforts.

35 Keywords: Child Sexual Abuse, Multimodal assessments, Bayesian logic, CSA investigation,

36 Decision making 
A Bayesian Decision-Support Tool for Child Sexual Abuse Assessment and Investigation Since the beginning of the 1980's, the number of Child Sexual Abuse (CSA)

allegations has increased in many Western countries (Ceci \& Bruck, 1995; Kauppinen, Sariola, \& Taskinen, 2000). Research suggests that both under- and over-reporting of CSA is a concern (Ceci \& Bruck, 1995; Lipian, Mills, \& Brantman, 2004; London, Bruck, Ceci, \& Shuman, 2005; Svedin \& Back, 2003). Underreporting refers to the fact that many cases of CSA never come to the authorities' attention. One reason for this is that some abused children do not disclose the abuse to adults and/or that adults fail to report such disclosures (London et al., 2005; Svedin \& Back, 2003). Naturally, the actual extent of this problem is difficult to reliably estimate. On the other hand, at least $5 \%-35 \%$ of CSA allegations are likely unfounded, suggesting over-reporting to also be very common. (Ceci \& Bruck, 1995). A recent study suggests that approximately $40 \%$ of CSA allegations in Finland are unfounded (Korkman, Antfolk, Fagerlund, \& Santtila, n.d.). Unfounded allegations can, for example, stem from misinterpretations of physical, psychological or behavioral symptoms displayed by the child, or from attention seeking and mental illness (O’Neal, Spohn, Tellis, \& White, 2014).

When investigating CSA allegations, the police frequently turn to experts for forensic interviewing of the alleged victim and for evaluating behavioral or psychological symptoms. Often, these experts also appear before court to provide expert testimony of relevance to the final judicial decision regarding abuse (Gratz \& Orsillo, 2006). Considering the importance of this expert testimony, expert evaluations need to be of the highest possible quality. Investigations of CSA allegations are, however, very challenging. Only a minority of allegations can be validated on the basis of physical evidence, such as pregnancy or the presence of semen (Muram, 2001). Approximately 70\% of CSA allegations lack strong corroborating evidence (i.e., medical or other material evidence such as photographs and 
videos; Herman, 2005). Contrary to what is commonly believed, unique behavioral symptoms are not valid indicators of CSA (Drach, Wientzen, \& Ricci, 2001). Another widely held belief is that the child's report is a very reliable source of information for deciding whether abuse has taken place or not (Berliner \& Conte, 1993; Lamb, 1994; Poole \& Lamb, 1998). The rationale behind this belief is that deliberate fabrication by children is rare and that false allegations are more likely to emanate from adults. Nevertheless, children are suggestible and may provide inaccurate information, especially when young and/or when considerable time has passed after the alleged event. While most experts agree that children can provide accurate reports, there is little doubt that a child's account can be distorted both by improper interviewing or by normal memory decay (Ceci \& Bruck, 1995).

Unsurprisingly, there is some controversy regarding how well experts perform as decision makers in allegations of CSA. Research suggests that expert evaluations are of alarmingly poor quality both in Finland (Korkman, Santtila, Westeråker, \& Sandnabba, 2008; Korkman, Santtila, \& Sandnabba, 2006) and in other countries (Cederborg, Orbach, Sternberg, \& Lamb, 2000; Davies, Westcott, \& Horan, 2000), and that expert decisions vary to such an extent that they cannot be considered reliable (Dror \& Cole, 2010; Horner, Guyer, \& Kalter, 1993a, 1993b). Moreover, legal experts' understanding of expert evaluations has also been investigated in two recent studies, and it is apparent that these assessments are laden with serious problems (Tadei, Finnilä, Korkman, Salo, \& Santtila, 2014; Tadei, Finnilä, Reite, Antfolk, \& Santtila, 2016).

\section{Bayesian Reasoning in Assessments of Allegations of Child Sexual Abuse}

In CSA assessments, the expert needs the ability to evaluate and integrate complex

4 and sometimes contradictory information to arrive at a conclusion. Research indicates that the reliability of clinical decisions is lower than the reliability of decisions based on actuarial (i.e., statistical) data (Dawes, 1994; Dawes, Faust, \& Meehl, 1989; Goldberg, Faust, Kleinmuntz, 
\& Dawes, 1991; Janus \& Prentky, 2003). Because human cognitive capacity of using statistical information is limited (Edwards \& von Winterfeldt, 1986; Tversky \& Kahneman, 1974), methods to deal with complex actuarial information might prove helpful in forensic decision making (Kochenderfer, 2015). Uncertainty about whether an event has occurred or not should be represented in terms of probabilities, and these probabilities should be adjusted based on new information (Baron, 1994; Dammeyer, 1998; Kuehnle, 1998). For example, information retrieved during the assessment should update the baseline probability of abuse. But the baseline probability should also consider the particular features of the child under investigation, and this probability could be used as the best possible starting point for further investigation. Statistical models based on Bayes' Theorem are particularly well suited for this (Herman, 2005; Wood, 1996). Bayes' Theorem assumes the baseline probability of an event is updated as new information becomes available. For example, let us assume the probability that a randomly picked 12-year-old Finnish girl has been sexually abused. According to the most recent population-based victimization (used in the present study), the baseline likelihood of her having been abused, when nothing else is known, is approximately .03. This is then the starting probability that has to be updated for each new piece of information that becomes available. Let us further imagine that the girl exhibits symptoms of anxiety. If we know that anxiety is exhibited by $60 \%$ of abused children and by $30 \%$ of non-abused children being assessed, how likely is it that she has been abused in light of her anxiety symptoms? To understand how the probability that she has been abused is updated given this new information, we can consider a pool of 1000 girls of her age. Of these girls, 30 (3.0\%) would have been abused and, of these girls, 18 (60\%) would show symptoms of anxiety. Of the 1000 girls, $970(97 \%)$ would not have been abused and, of these girls, 291 (30\%) would show anxiety. Hence, $309(18+291)$ girls show anxiety but only $18(5.8 \%)$ have been abused. This means that, compared to the baseline probability (.03), the observation of anxiety almost 
112 doubles the probability of the girl having been abused. With $H$ meaning hypothesis (the girl

113 has been abused), and $E$ meaning evidence (the girl shows anxiety symptoms), the reasoning

114 can be expressed as follows

$$
p(H \mid E)=\frac{p(E \mid H) p(H)}{p(E)}=\frac{0.6 \times 0.03}{0.018+0.291} \approx 0.058
$$

116 Nevertheless, .058 is still a low probability and the option that she has not been abused is

117 much more probable (.942). For each new piece of information, the probability of abuse can

118 be updated.

\section{The Current Study}

Many studies have demonstrated that not only laypeople, but also people with a

121 background in behavioral sciences, often find it difficult to use statistical information correctly (Lehman, Lempert, \& Nisbett, 1988; Levett, Danielsen, Kovera, \& Cutler, 2005;

123 Vidmar, 2005). Some authors suggest this is due to the use of formulas and abstract

124 probabilities (Cosmides \& Tooby, 1996; Gigerenzer, 2002), while other authors think the

125 underlying theoretical concepts are difficult to understand for non-mathematicians (Fenton \&

126 Neil, 2011). Multi-modal assessments, that is, assessments using multiple sources of

127 information, necessitate a meticulous overview and integration information from available

128 (and missing) evidence. To deal with the problems described and improve the reliability in

129 assessments of CSA allegations, we aimed to develop a computerized statistical-model that

130 calculates the starting probability of a suspicion of CSA being true (i.e., that the child in

131 question actually has been abused). To do this we used available victimization data from a

132 large representative sample in Finland. Data retrieved from these victimization data were

133 analyzed using Bayesian statistics.

\section{Methods}

\section{Context and Sample}


All data used in our research were part of a larger project focusing on different forms of violence against children and adolescents in Finland. The project was managed by the Police University College in collaboration with the Finnish Youth Research Society (Ellonen,

140 Fagerlund, Kääriäinen, Peltola, \& Sariola, 2013). The most recent data collection was carried 141 out in 2013, and is the third of its kind. Two other data collections were carried out in 1988

142 (Sariola, 1988) and in 2008 (Ellonen, Kääriäinen, Salmi, \& Sariola, 2008). The project aimed

143 to quantify the prevalence of several phenomena, such as crime experiences, peer

144 victimization, cyber-bullying, and sexual abuse. Alongside these phenomena, the data also

145 include demographic data of the child and its family, and personal matters (e.g., health status,

146 family employment situation, use of drugs or alcohol). Because research shows that the

147 prevalence and nature of child sexual abuse has changed over the years (Laaksonen et al.,

148 2011), we decided to use only data from the 2013 collection.

\section{Participants}

The 2013 data collection included reports from 11,364 respondents in total. The

151 participants attended either the $6^{\text {th }}$ or the $9^{\text {th }}$ grade in different schools around Finland. To

152 gather a representative sample of $6^{\text {th }}$ and $9^{\text {th }}$ graders, a stratified cluster sampling procedure

153 with the school class as sample unit, was employed. The sample stratification was made

154 according to province, municipality, and school size. Because the samples were drawn using

155 the class information of the year before the data collections, the authors were unable to

156 calculate the exact response rate (for more details about the dataset, see Ellonen et al., 2013).

157 The response rate is instead known for the two previous versions of the questionnaire (89\% in

$158 \quad 1988 ; 88 \%$ of $6^{\text {th }}$ and $64 \%$ of 9 th grade pupils in 2008$)$.

159 From the original dataset, we excluded 566 respondents because they had not provided

160 answers for key questions related to sexual abuse, 33 respondents because they did not answer

161 the questions related to their and/or the offender's age at the time of the abuse, and 100 
162

163

164

165

166

167

168

169

170

171

172

173

174

175

176

177

178

179

180

181

182

183

184 Statistical Analysis

185

186

respondents because the participant either $(i)$ declared to have been abused but they reported to be older at the time of abuse than they were at the time of the survey, or (ii) declared to have been abused, but the age difference between them and the offender was below 5 years, although this minimum age difference was explicitly formulated in the question. Thus, our final dataset consisted of reports from 10,665 children. Of the participants, $51.3 \%(n=5451)$ were girls and $48.7 \%(n=5184)$ were boys ( 30 children did not report their gender).

\section{Measures and Definitions}

We defined child sexual abuse as the occurrence of one or more experiences of the events listed in Table 1 before age 17, along with at least a 5-year age difference between the victim and the offender. We acknowledge that this operationalization also defined consensual sexual relation with a 5-years older person as abuse. This could have been avoided by also considering answers to the question: "Did you see the situation as sexual abuse?". The negative consequence of this would have been not considering as victims the children, who, in a juridical meaning, would have been abused, without perceiving the event as sexual abuse. Subsequently, the final decision was to avoid false negatives (i.e., not to define a real CSA event as such) at the risk of false positives (i.e., define the event as CSA when it is not). We also want to point out that this decision does not invalidate the logic of the subsequent analyses. All subsequent analyses could be conducted with different operational definitions of abuse, depending on the legal context in which they are intended to be used.

Classifier. The aim of a classifier is to determine to which category a designated class variable $H$ belongs given some evidence provided by a set of feature variables $E_{1}, \ldots, E_{d}$. For 
a classifier to be accurate, the features need to be informative in discriminating between the different classes of $H$. A classifier is typically trained in a supervised manner on labeled data containing joint observations of the features and class variable. In our study, we wanted to investigate if CSA can reliably be predicted given self-reported information about the child's

191 family, relations with peers, past experiences with crime events, use of drugs or alcohol and

192 other life events unrelated to the possible CSA. The data were extracted from questionnaires and represented as categorical variables.

In our procedure we considered a probabilistic classifier, which assigns the class label

195

to the category with the highest conditional probability given the values of the feature

variables. In addition to specifying the most probable class, the updated class distribution also provides valuable information regarding the uncertainty of the proposed class label. Using Bayes' theorem, the classification criterion of assigning $H=h$ given the feature values $E_{1}=$ $e_{1}, \ldots, E_{d}=e_{d}$ can be inferred from a generative model and formulated as

$$
\underset{h \in \mathcal{H}}{\arg \max }\left[p\left(E_{1}=e_{1}, \ldots, E_{d}=e_{d} \mid H=h\right) p(H=h)\right]
$$

where $\mathcal{H}$ is the set of class categories. Without additional assumptions, a practical limitation of (1) is that the number of parameters required to model the joint feature distribution grows exponentially with the number of features. The most common way of dealing with this is to assume a naïve Bayes structure. A naïve Bayes classifier assumes that all feature variables are conditionally independent given the class variable, allowing a factorization of the joint feature distribution according to

$$
p\left(E_{1}, \ldots, E_{d} \mid H\right)=\prod_{i=1}^{d} p\left(E_{i} \mid H\right),
$$

In other words, the high-dimensional multivariate distribution in (1) can be modeled as a product of $d$ low-dimensional univariate distributions. In a broader perspective, the naïve Bayes classifier falls in the graphical model family of Bayesian networks (directed graphical 
models), which have been developed as a means to model multivariate distributions (see

Koller \& Friedman, 2009, for an in-depth overview of the theory of Bayesian networks). One

211 of the key features of Bayesian networks is the use of directed acyclic graphs to compactly

212 represent and visualize complex dependence structures over collections of variables. In

213 particular, the dependence structure assumed by the naïve Bayes classifier is depicted in

214 Figure 1(a).

of handling missing data. In fact, summing out a non-observed feature variable is equivalent

to simply omitting the corresponding conditional distribution from (2). This particular property is very useful in terms of updating the class distribution and performing feature selection, especially in our case where the training data has been collected through questionnaires containing many non-answered questions.

Rather than using a single naïve Bayes classifier, we propose using a collection of profile-specific classifiers. In this approach, there is a different model for each context specified by a profile variable. This enables modeling situations where the feature distributions are expected to differ between the profiles. When taking a profile variable $S$ into

228 account, the classification criterion can be formulated as

$$
\underset{h \in \mathcal{H}}{\arg \max }\left[p(S=s) p(H=h \mid S=s) \prod_{i=1}^{d} p\left(E_{i}=e_{i} \mid H=h, S=s\right)\right] .
$$

230 Note that the features are still conditionally independent given the class and profile variables.

231 In Figure 1(b), the original naïve Bayes structure in Figure 1(a) has been updated to illustrate 232 the additional profile variable. 
Feature selection. Feature selection is the process of selecting an informative subset

of non-redundant features from a set candidate features. An identified feature is informative if it is useful for discriminating between the class categories. In addition to being marginally informative, a good feature should also be non-redundant in the sense that it should remain informative given the other features. In particular, the joint effect of several strongly correlated features is easily over-emphasized in a naïve Bayes classifier, since the joint effect is approximated as the sum of the individual effects. In this work, we take inspiration from the structure learning field of Bayesian networks and propose a feature selection technique that is designed to select features that are both informative and non-redundant. dependence between $E$ and $H$ in the presence of $E^{\prime}$. In other words,

$$
b f\left(E ; H \mid E^{\prime}\right)=m\left(E \mid E^{\prime}, H\right)-m\left(E \mid E^{\prime}\right),
$$

245 where $m\left(E \mid E^{\prime}, H\right)$ is the $\log$ marginal likelihood of $E$ given $E^{\prime}$ and $H$, and $m\left(E \mid E^{\prime}\right)$ is the $\log$ 246 marginal likelihood of $E$ given $E^{\prime}$ (see Heckerman, Geiger, \& Chickering, 1995). Values 247 above zero support $E$ and $H$ being dependent given $E^{\prime}$, and the higher the value the stronger is 248 the support. Analogously, values below zero support conditional independence between $E$ and $249 \quad H$ given $E^{\prime}$.

$250 \quad$ Furthermore, let $\boldsymbol{E}_{\text {cand }}$ denote a set of candidate features and let $\boldsymbol{E}_{\text {curr }} \subset \boldsymbol{E}_{\text {cand }}$ denote 251 a subset of features already selected from the candidate set. The score of a candidate feature $252 E \in \boldsymbol{E}_{\text {cand }} \backslash \boldsymbol{E}_{\text {curr }}$ is then defined as

$$
\operatorname{score}\left(E \mid \boldsymbol{E}_{\text {curr }}\right)=\min _{E^{\prime} \in \boldsymbol{E}_{\text {curr }}}\left[b f\left(E ; H \mid E^{\prime}\right)\right]
$$

254 The score will thus favor features that are informative also in the presence of each of the 255 already added features. If no feature has been added, the above score is reduced to measuring 256 marginal dependence between $E$ and $H$ as quantified by $b f(E ; H)$. 

selecting a set of features:

2. IF $\operatorname{score}\left(E^{*} \mid \boldsymbol{E}_{\text {curr }}\right)>0$ : add $E^{*}$ to $\boldsymbol{E}_{\text {curr }}$ and repeat 1-2, ELSE return $\boldsymbol{E}_{\text {curr }}$. split according to the different profiles and the feature selection algorithm is then run separately for each profile. Taking the profile-specific feature sets into account, our classification criterion can finally be formulated as

$$
\underset{h \in \mathcal{H}}{\arg \max }\left[p(S=s) p(H=h \mid S=s) \prod_{i=1}^{d} p\left(E_{i}=e_{i} \mid H=h, S=s\right)^{\mathbf{I}\left(E_{i} \in E(s)\right)}\right],
$$

266 where $\boldsymbol{E}(s)$ is the feature set associated with profile $S=s$ and $\mathbf{I}\left(E_{i} \in \boldsymbol{E}(s)\right)$ is an indicator

267 function taking on value 1 if $E_{i} \in \boldsymbol{E}(s)$ and value 0 if $E_{i} \notin \boldsymbol{E}(s)$. A useful property of the 268 above distribution is that it can still be captured by a single Bayesian network using the 269 concept of context-specific independence (Boutilier, Friedman, Goldszmidt, \& Koller, 1996; 270 Pensar, Nyman, Koski, \& Corander, 2015).

Classifier validation. To evaluate the performance of the classifier, we computed the 272 Receiver Operating Characteristics (ROC) curves (Fawcett, 2004). A ROC curve is a graphical plot that illustrates the performance of a binary classifier by plotting the true

274 positive rate against the false positive rate. By varying the threshold value for assigning the 275 class label we obtain different points in ROC space. The complete curve can be obtained by

276 letting the threshold value incrementally increase in small steps from 0 to 1 , since the 277 considered classifier returns a probability. To quantify the ROC curve in a single numerical measure we also calculated the Area Under the Curve (AUC). Since the AUC is a proportion 
280

should have an AUC lower than 0.5, which corresponds to random guessing. The AUC can be interpreted as the probability that a random positive instance is ranked higher than a random negative instance (assuming that positives rank higher than negatives). For a more robust assessment of the out-of-sample performance of the classifier, we used cross-validation where the data were randomly split into a training set and a test set of equal size. The classifier parameters were learned using the training data and the classifier was then evaluated on the holdout test data. To reduce variability, the cross-validation procedure was repeated 100 times, that is, the final results are averages over 100 ROC curves and corresponding AUCs.

Instruments. All numerically demanding procedures were implemented and run in MATLAB.

Graphical Model. The final model was also manually constructed in AgenaRisk (Fenton \& Neil, 2012), which provides a more user-friendly graphical interface. Figure 2 shows an example of the Bayesian classifier in AgenaRisk and how data are entered. The classifier starts from the probability that the CSA suspicion is true given the base rate prevalence in the general population. After this, this probability is updated as more evidence is added.

[Insert Figure 2 about here]

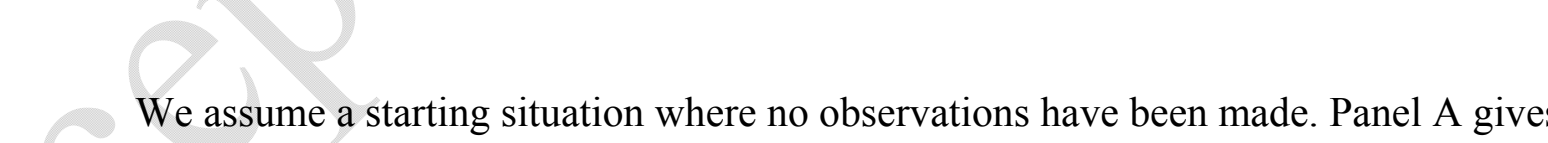

the baseline probability of .03. In panel $\mathrm{B}$, this probability is updated given that the girl replied Yes to the question "Have you ever tried drugs (e.g., hashish or ecstasy)?". Here, the probability of having tried drugs is 0.194 if the child has been abused and 0.019 if the child has not been abused. In panel $\mathrm{C}$, the probability is updated given that the child has dinner with the adults she lives with at least twice a week, and that she has not been victim of any 
physical attack in the last 12 months. After considering the use of drugs, the frequency of dinner with the family, and the absence of any recent physical attack, the probability of sexual abuse is approximately .15.

After having selected the profile variable and the corresponding sets of feature variables, we built a classifier in form of a Bayesian network in AgenaRisk. The network, which follows the structure illustrated in Figure 1(b), is composed of the following variables, which are known as nodes in a graphical model: a profile node, a set of feature nodes, and a result (or class) node. The result node gives the probability that the assessed child has been sexually abused. This node is linked to the profile node and to all the features in the classifier. After specifying the profile, only nodes that are included in the feature set for that specific profile can influence the distribution of the result node, while nodes outside the feature set will have no influence. In practice, this is achieved by imposing regularities within the feature distributions according to the concept of context-specific independence.

If the information is available, all nodes linked to a profile can be defined as True or False or by choosing among the possible answers for the given classifier. For example, the question "How often do you eat dinner with one or both of your parents (or those adults who you live with)?" has two possible answers: "Several times a week or more" and "Once a week or less)". When information is lacking a node can be left undefined. When new evidence is inserted into the classifier, by assigning a value to a node, the classifier automatically updates the probability of sexual abuse by performing inference in the model.

\section{Results}

We first calculated the CSA prevalence in Finland, dividing the sample into girls and boys. The analyses indicate that the CSA base rate for boys (age 0-16) was .007 and 0.03 for girls. We also experimented dividing the sample according both the gender and the age (0-12 
and 13-16) but the analyses showed that using gender was sufficient (i.e., the age information did not increase the accuracy of the classifier).

After this, we conducted the feature selection. In total we identified 42 significant features that could be used to assess the probability that an assessed child has been sexually abused. We identified 28 girl-specific features, 17 boy-specific features, and 3 general features valid for both girls and boys. See Appendix for each feature, the name used in the classifier, the full question asked in the survey, and the Bayes factor, which is a measure of the marginal dependence between the feature and the class variable. The order of the features in the table is the same as the order in which they were selected by the feature selection method. The order a rough estimate of the importance of a feature in the presence of the other features.

As a final evaluation step, we calculated the $R O C$ curves. These were calculated for both genders separately. The $A U C$ values indicate that the FICSA shows excellent diagnostic performance (Figure 3). The performance is somewhat better for boys $(A U C=.97)$ than for girls $(A U C=.88)$.

\section{The FICSA Graphical Model}

[Insert Figure 3 about here]

Finally, Figure 4 shows the classifier built in AgenaRisk. The classifier is visually divided in three main parts: on the left the features valid only for girls, on the right the features valid only for boys, in the middle the features valid for both genders. The squared node at the top permits the user to select the gender of the assessed individual. After this selection, all features that are irrelevant for the chosen gender are disregarded by the software. The target node gives the final outcome probability for sexual abuse. Features are grouped 
according to themes. For girls these are (in clockwise order) Friends, Family, Psychological status, Substance abuse, Cyber-violence, and Violent experiences. For boys these are (in clockwise order) Friends, Cyber-violence, Family, Sibling or peer violence, and Violent experiences. The feature theme shared between girls and boys is Sexual experiences.

[Insert Figure 4 around here]

To further clarify how the FICSA works, we decided to create two different fictive scenarios. Both scenarios describe a CSA allegation regarding 11-years old girls. Here, we use the features in FICSA to arrive at a probability that the girl has been abused. Table 2 shows the features of relevance for CSA allegations with girls as the possible victim. The full question related to each variable can be found in the Appendix.

\section{[Insert Table 2 about here]}

Case 1 describes a girl who is severely bullied by schoolmates, both in person and through social networks. She is shy and has never reported her problems to anyone but her parents. She once kissed a boy from her class and is, since then, object of her female classmates' jealousy. They bully her both in person and by phone messages and have threatened to hurt her physically. During the last month she has been bullied online by people both known and unknown to her. We know that her family eats dinner together every day and that she has never been victim of physical or psychological violence. The parents are considering to send her to another school, because the situation is affecting the girl's wellbeing. She has difficulties sleeping and cannot focus on her studies. She never smoked or used drugs, but her parents let her have a glass of sparkling wine on special occasions. 

during evenings and nights. When the father is not home, she usually hangs out with a group of slightly older boys who gather in the main square or in the park close to her home. The father frequently complains that she is not doing her household chores, and that her mother would be as disappointed in her as he is. Sometimes he calls her names too. She smokes, and she drinks almost weekly. She does not use the Internet. Finally, it has become known that

386 she has satisfied some of her classmates sexual requests, and that she was victim of violent aggression 3 months ago.

In both cases the baseline probability of sexual abuse is .03, but the FICSA gives two different probabilities for abuse after updating the prior using case-specific features. In Case 1

390 the probability is .27 . This is considerably higher than the baseline probability, but,

391 conversely, the probability of no abuse is .73. In Case 2 the probability of abuse is .84 and the 392 probability of no abuse is .16 . accessible background information to assist clinical decision making in CSA allegations. To do this we used demographical information from a large, representative population-based

398 victimization study. Our final model included 42 features in total and showed excellent 399 diagnostic utility. There are, however, some concerns that currently restrict its feasibility.

400 Some of these concerns pertain to the model assumptions, while other concerns pertain to the 401 validity and use of the estimated abuse probability.

\section{Model Assumptions}

403 Although the FICSA is based on sound logic, the outcome is also dependent on the 404 validity of the premises, that is, the validity and reliability of the data entered into the 
classifier. Here, a first concern is the time interval between the experienced CSA and participation in the questionnaire. If participation took place immediately after the event, we could be sure that all of a child's answers described the situation before the abuse. In such a case, variables related to CSA, would be actual predictors. In the current study, instead, some of the variables that were included in the FICSA could also describe the situation after the event. For example, the feature "Drugs", that refers to the question "Have you ever tried drugs (e.g. hashish or ecstasy)?" can also be a consequence of abuse (Hornor, 2010). This might appear to undermine the validity of the current method. We argue, however, that the chronological order of events has no impact in the decision making in assessments of CSA suspicions. If at the time of the assessment, a variable is known and this variable is reliably associated with experiencing abuse in the past (or future) it will contribute valid information. An example that clarifies this is the presence memories of the abuse, which, invariably would appear after the event and which are useful evidence in the investigation.

Another concern pertains to the operational definition of CSA, which in the current study includes a minimum age difference between victim and offender. To reflect Finnish legal practice, this age difference was set at 5 years in the victimization study. This definition excludes all sexual relations, in which the age difference is lower, and involves, for example, sexual relations between a 12-year old and a 14-year old. In such cases the law itself is less precise, and courts have to evaluate the nature of the event, the type of relationship between the individuals and so on. Similarly, all sexual relations involving a minor, where the age difference between the two parts is over 5 years are considered CSA, even if the parties themselves might view them as consensual. We also considered using the question: "Did you see the situation as sexual abuse?" as a criterion. In this way it would have been possible to exclude sexual acts perceived to be consensual and get a stricter definition of CSA. Because some children may not perceive an abusive act as sexual abuse due to, for example, cognitive 
430

431

432

difficulties or being victims of manipulation, we refrained from using this criterion.

Furthermore, an allegedly consensual relation could relatively easily be demonstrated during the investigation and the possible trial, and therefore it poses few practical problems.

\section{The Validity and Use of the Estimated Abuse Probability}

The FICSA gives a value ranging between 0 (abuse very unlikely) and 100 (abuse very likely) that expresses the probability that the CSA has actually taken place and the case can be substantiated. Because it is improbable that the result will be either 0 or 100 , and in most cases the model will give a value somewhere in between these extremes, it is important to consider the interpretation of the value in attempting to reach a final decision. For this purpose, the ROC curves in Figure 3 provide valuable information by showing the estimated trade-offs between true and false positives that are obtained for different threshold class probabilities. Another important next step will be to compare the outcome of validated real cases (i.e., cases where an offender has credibly confessed or cases where the alleged victim has credibly retracted the allegation) with the results of the method, and assess the trade-off between false and true positives in actual assessed CSA allegations. Even in the cases where the classifier gives a very high value, it is vital to also consider the possibility that CSA has not yet taken place (and, of course, potentially never will). Because the FICSA rests on demographic and background variables, it is very important to give full consideration to other evidence. Only using demographic and background variables, our method demonstrated excellent capacity to discriminate between abused and not abused children. Depending on the gender, the AUC values ranged between .88 and .97 . We conclude that the FICSA might contribute important information in assessments and investigations of child sexual abuse suspicions.

\section{Conclusions and Future Directions}


If the limitations described can be addressed and the method's validity can be

demonstrated, we argue that Bayesian classifiers provide a powerful tool that can consider multiple pieces of evidence used to providing a starting probability for CSA assessments, and support decision making in assessment of CSA allegations. It could also guide the

459 information. Importantly, we do not think FICSA should in any way replace the gathering and

460 evaluation of traditional evidence. Rather, we think that FICSA can be used to provide a best461 possible starting point for further investigation. As the relationship between information

462 modeled here and other forms of information (e.g., medical assessments, interview-based 463 evidence) becomes known, the FICSA could be updated to also take this information into 464 account.

465 Another important step to take is to cross-validate the selection of variables (and their 466 weights) in other representative samples. Gathering local data would also be necessary for the 467 classifier to be useful in other populations. This is because it is likely that several indicators 468 vary over time and place, and that indicators that are currently valid in Finland are not 469 necessarily valid elsewhere. 
BAYESIAN MODEL FOR CHILD SEXUAL ABUSE INVESTIGATION

471

472

473

474

475

476

477

478

479

480

481

482

483

484

485

486

487

488

489

490

491

492

493

494

495

\section{References}

Baron, J. A. (1994). Uncertainty in Bayes. Medical Decision Making, 14(1), 46-51. https://doi.org/10.1177/0272989X9401400106

Berliner, L., \& Conte, J. R. (1993). Sexual abuse evaluations: Conceptual and empirical obstacles. Child Abuse and Neglect, 17(1), 111-125. https://doi.org/10.1016/01452134(93)90012-T

Boutilier, C., Friedman, N., Goldszmidt, M., \& Koller, D. (1996). Context-Specific Independence in Bayesian Networks. In Proceedings of the Twelfth Conference Conference on Uncertainty in Artificial Intelligence (Vol. 4, pp. 115-123). Morgan Kaufmann Publishers Inc..

Ceci, S. J., \& Bruck, M. (1995). Jeopardy in the courtroom: A scientific analysis of children's testimony. Jeopardy in the courtroom A scientific analysis of childrens testimony. American Psychological Association.

Cederborg, A. C., Orbach, Y., Sternberg, K. J., \& Lamb, M. E. (2000). Investigative interviews of child witnesses in Sweden. Child Abuse and Neglect, 24(10), 1355-1361. https://doi.org/10.1016/S0145-2134(00)00183-6

Cosmides, L., \& Tooby, J. (1996). Are humans good intuitive statisticians after all? Rethinking some conclusions from the literature on judgment under uncertainty. Cognition, 58(1), 1-73. https://doi.org/10.1016/0010-0277(95)00664-8

Dammeyer, M. D. (1998). The assessment of child sexual abuse allegations: using research to guide clinical decision making. Behavioral Sciences \& the Law, 16(1), 21-34.

Davies, G. M., Westcott, H. L., \& Horan, N. (2000). The impact of questioning style on the content of investigative interviews with suspected child sexual abuse victims. Psychology, Crime \& Law, 6(2), 81-97. https://doi.org/10.1080/10683160008410834 Dawes, R. M. (1994). House of cards: Psychology and psychotherapy built on myth. New 
York: Free Press.

Dawes, R. M., Faust, D., \& Meehl, P. E. (1989). Clinical versus actuarial judgment. Science, 243(4899), 1668-1674.

Drach, K. M., Wientzen, J., \& Ricci, L. R. (2001). The diagnostic utility of sexual behavior problems in diagnosing sexual abuse in a forensic child abuse evaluation clinic. Child Abuse and Neglect, 25(4), 489-503.

Dror, I. E., \& Cole, S. a. (2010). The vision in "blind" justice: expert perception, judgment, and visual cognition in forensic pattern recognition. Psychonomic Bulletin $\mid \&$ Review, $17(2), 161-167$.

Edwards, W., \& von Winterfeldt, D. (1986). On cognitive illusions and their implications. Southern California Law Review, 59(2), 401-451.

Ellonen, N. (Police U. C., Fagerlund, M. (Police U. C., Kääriäinen, J. (Police U. C., Peltola, M. (Finnish Y. R. S., \& Sariola, H. (Central U. for C. W. (2013). Child Victim Survey 2013 [dataset]. Version 1.0 (2015-03-16). Finnish Social Science Data Archive. Retrieved from http://urn.fi/urn:nbn:fi:fsd:T-FSD2943

Ellonen, N. (Police U. C., Kääriäinen, J. (Police U. C., Salmi, V. (National R. I. of L. P., \& Sariola, H. (Central U. for C. W. (2008). Child Victim Survey 2008 [dataset]. Version 2.0 (2014-09-19). Finnish Social Science Data Archive. Retrieved from http://urn.fi/urn:nbn:fi:fsd:T-FSD2416

Fawcett, T. (2004). ROC Graphs : Notes and Practical Considerations for Researchers. ReCALL, 31(HPL-2003-4), 1-38.

Fenton, N., \& Neil, M. (2011). Avoiding probabilistic reasoning fallacies in legal practice using Bayesian networks. Australian Journal of Legal Philosophy, 36, 114-150.

Fenton, N., \& Neil, M. (2012). Risk Assessment and Decision Analysis with Bayesian Networks. Boca Raton, FL: Taylor and Francis Group. 
BAYESIAN MODEL FOR CHILD SEXUAL ABUSE INVESTIGATION

Gigerenzer, G. (2002). Reckoning with Risk: Learning to Live with Uncertainty. London: Penguin Books.

Goldberg, L. R., Faust, D., Kleinmuntz, B., \& Dawes, R. M. (1991). Clinical versus statistical prediction. Thinking clearly about psychology: Essays in honor of Paul E. Meehl, 1, 173264.

Gratz, K. L., \& Orsillo, S. M. (2006). Scientific Expert Testimony in CSA Cases: Legal, Ethical, and Scientific Considerations. Clinical Psychology: Science and Practice, 10(3), $358-363$.

Heckerman, D., Geiger, D., \& Chickering, D. M. (1995). Learning Bayesian Networks: The Combination of Knowledge and Statistical Data. Machine Learning, 20(3), 197-243.

Herman, S. (2005). Improving decision making in forensic child sexual abuse evaluations. Law and Human Behavior, 29(1), 87.

Horner, T. M., Guyer, M. J., \& Kalter, N. M. (1993a). Clinical expertise and the assessment of child sexual abuse. Journal of the American Academy of Child and Adolescent Psychiatry, 32(5), 925-931.

Horner, T. M., Guyer, M. J., \& Kalter, N. M. (1993b). The biases of child sexual abuse experts: believing is seeing. Journal of the American Academy of Psychiatry and the Law Online, 21(3), 281-92.

Hornor, G. (2010). Child Sexual Abuse: Consequences and Implications. Journal of Pediatric Health Care, 24(6), 358-364.

Janus, E. S., \& Prentky, R. A. (2003). Forensic use of actuarial risk assessment with sex offenders: Accuracy, admissibility and accountability. American Criminal Law Review, 40, $1443-1499$.

Kauppinen, S., Sariola, H., \& Taskinen, S. (2000). Child sexual abuse suspicions quadrupled in 15 years. Helsinki: Stakes. 
Kochenderfer, M. J. (2015). Decision making under uncertainty: theory and application. MIT Press.

Koller, D., \& Friedman, N. (2009). Probabilistic Graphical Models: Principles ad Techniques. MIT Press.

Korkman, J., Antfolk, J., Fagerlund, M., \& Santtila, P. (n.d.). in preparation.

Korkman, J., Santtila, P., \& Sandnabba, N. K. (2006). Dynamics of verbal interaction between interviewer and child in interviews with alleged victims of child sexual abuse. Scandinavian Journal of Psychology, 47(2), 109-119.

Korkman, J., Santtila, P., Westeråker, M., \& Sandnabba, N. K. (2008). Interviewing techniques and follow-up questions in child sexual abuse interviews. European Journal of Developmental Psychology, 5(1), 108-128.

Kuehnle, K. (1998). Child sexual abuse evaluations: The scientist-practitioner model. Behavioral Sciences and the Law, 16(1), 5-20.

Laaksonen, T., Sariola, H., Johansson, A., Jern, P., Varjonen, M., von der Pahlen, B., \& Santtila, P. (2011). Changes in the prevalence of child sexual abuse, its risk factors, and their associations as a function of age cohort in a Finnish population sample. Child Abuse \& Neglect, 35(7), 480-90.

Lamb, M. E. (1994). The investigation of child sexual abuse: An interdisciplinary consensus statement. Child Abuse \& Neglect, 18(12), 1021-1028.

Lehman, D. R., Lempert, R. O., \& Nisbett, R. E. (1988). The effects of graduate training on reasoning: Formal discipline and thinking about everyday life events. American Psychologist, 43, 431-443.

Levett, L., Danielsen, E., Kovera, M. B., \& Cutler, B. (2005). The Psychology of Jury and Juror Decision Making. In Psychology and Law : An Empirical Perspective (pp. 365406). 
Lipian, M. S., Mills, M. J., \& Brantman, A. (2004). Assessing the verity of children's allegations of abuse: A psychiatric overview. International Journal of Law and Psychiatry, 27(3), 249-263.

London, K., Bruck, M., Ceci, S. J., \& Shuman, D. W. (2005). Disclosure of Child Sexual Abuse: What Does the Research Tell Us About the Ways That Children Tell? Psychology, Public Policy, and Law, 11(1), 194-226.

Muram, D. (2001). The medical evaluation in cases of child sexual abuse. Journal of Pediatric and Adolescent Gynecology, 14(2), 55-64.

O’Neal, E. N., Spohn, C., Tellis, K., \& White, C. (2014). The truth behind the lies: The complex motivations for false allegations of sexual assault. Women \& Criminal Justice, 24(4), 324-340.

Pensar, J., Nyman, H., Koski, T., \& Corander, J. (2015). Labeled directed acyclic graphs: a generalization of context-specific independence in directed graphical models. Data Mining and Knowledge Discovery, 29(2), 503-533.

Poole, D. A., \& Lamb, M. E. (1998). Investigative interviews of children: A guide for helping professionals. American Psychological Association.

Sariola, H. (Central U. for C. W. (1988). Child Victim Survey 1988 [dataset]. Version 1.0 (2009-01-15). Finnish Social Science Data Archive. Retrieved from http://urn.fi/urn:nbn:fi:fsd:T-FSD2406

Svedin, C. G., \& Back, M. (2003). Varför berättar de inte: Om att utnyttjas i barnpornografi [Why don't they tell?: Being used in child pornography]. Falun: Rädda Bamen.

Tadei, A., Finnilä, K., Korkman, J., Salo, B., \& Santtila, P. (2014). Features used by judges to evaluate expert witnesses for psychological and psychiatric legal issues. Nordic Psychology, 66(4), 239-253. https://doi.org/10.1080/19012276.2014.963648

Tadei, A., Finnilä, K., Reite, A., Antfolk, J., \& Santtila, P. (2016). Judges’ Capacity to 
BAYESIAN MODEL FOR CHILD SEXUAL ABUSE INVESTIGATION

596 Evaluate Psychological and Psychiatric Expert Testimony. Nordic Psychology, 68(3), $597 \quad 204-217$.

598 Tversky, A., \& Kahneman, D. (1974). Judgement under Uncertainty: Heuristics and Biases. $599 \quad$ Science, 185(4157), 1124-1131.

600 Vidmar, N. (2005). Expert evidence, the adversary system, and the jury. American Journal of $601 \quad$ Public Health, 95(S1), S137-S143.

602 Wood, J. M. (1996). Weighing Evidence in Sexual Abuse Evaluations: An Introduction to 603 Bayes's Theorem. Child Maltreatment, 1(1), 25-36.

604 
605 Table 1

606 Events Considered Sexual Abuse

Receive a proposal to do anything sexual

Offender shows genitals

Victim shows genitals

Offender touches victim's genitals over the clothes

Victim touches offender's genitals over the clothes

Offender touches victim's genitals under the clothes

Victim touches offender's genitals under the clothes

Petting

Imitation of sexual intercourse, without penetration Sexual intercourse, with penetration 
Table 2

Two Examples of CSA Allegations Regarding an 11-Year Old Girl

\begin{tabular}{|c|c|c|}
\hline Variable & Case 1 & Case 2 \\
\hline \multicolumn{3}{|l|}{ Friends } \\
\hline Friends age & Same age & Older but still $<18$ \\
\hline Getting on with adults more than peers $(6 \mathrm{M})$ & Not true & Not true \\
\hline Sexual experience with peer, no touch & Yes & Yes \\
\hline Public places $10 \mathrm{pm}-12 \mathrm{pm}$ & Never & Fairly often \\
\hline \multicolumn{3}{|l|}{ Family } \\
\hline Insulted by father $(>12 \mathrm{M})$ & No & Yes \\
\hline Pushed or shaken by father $(>12 \mathrm{M})$ & No & No \\
\hline Dinner in family & Several times a week or more & Once a week or less \\
\hline \multicolumn{3}{|l|}{ Psychological Status } \\
\hline Worrying a lot $(6 \mathrm{M})$ & Certainly true & Somewhat true \\
\hline \multicolumn{3}{|l|}{ Addictions } \\
\hline Drugs & No & No \\
\hline Alcohol & Yes & Yes \\
\hline Smoke cigarettes & Have never smoked & Smoke, but not daily \\
\hline \multicolumn{3}{|l|}{ Cyber-Violence } \\
\hline Bullied or insulted by text messages (12M) & Yes & No \\
\hline Threatening messages by phone (12M) & Yes & No \\
\hline Sexually harassing messages by phone (12M) & No & No \\
\hline Bad rumors on Web $(12 \mathrm{M})$ & Yes & No \\
\hline Rude behavior from unknown on Web (12M) & Yes & No \\
\hline Sexy photos or videos requested on Web (12M) & No & No \\
\hline \multicolumn{3}{|l|}{ Violent Experiences } \\
\hline Attack threat $(12 \mathrm{M})$ & Yes & No \\
\hline
\end{tabular}




$\begin{array}{lll}\text { Attack threat }(>12 \mathrm{M}) & \text { No } & \text { No } \\ \text { Theft }(12 \mathrm{M}) & \text { No } & \text { No } \\ \text { Theft }(>12 \mathrm{M}) & \text { No } & \text { No } \\ \text { Hit or attacked }(12 \mathrm{M}) & \text { No } & \text { No } \\ \text { Hit or attacked }(>12 \mathrm{M}) & \text { No } & / \\ \text { Drunk or high when victim of theft } & / & \\ \text { Incident described to mother }(12 \mathrm{M}) & \text { No } & \\ \text { Sexual Experiences } & & \text { No } \\ \text { Sex with Bf or Gf } & \text { No } & \text { Yes } \\ \text { Sex, anal or oral, real or attempted, with peers } & \text { No } & \text { No } \\ \text { Sexual proposal on Web by unknown }(12 \mathrm{M}) & \text { No } & \end{array}$


609

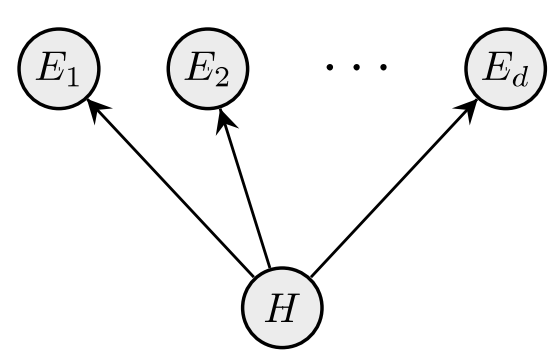

(a)

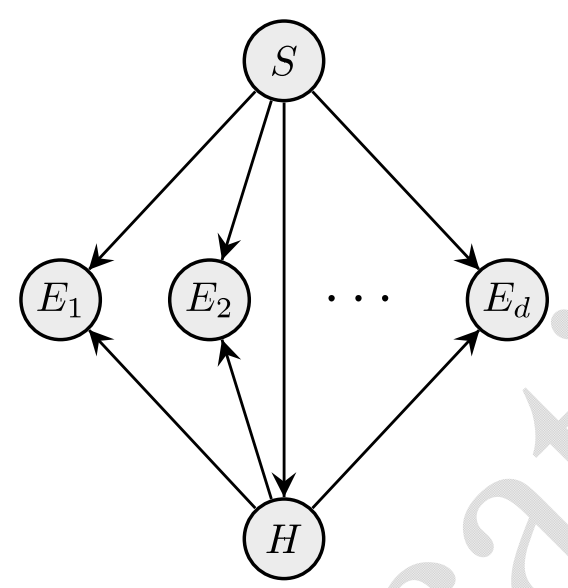

(b)

610

611 Figure 1. (a) The naïve Bayes dependence structure represented by a directed acyclic graph;

612 (b) The profile-specific naïve Bayes structure represented by a directed acyclic graph.

613

614

615

616 

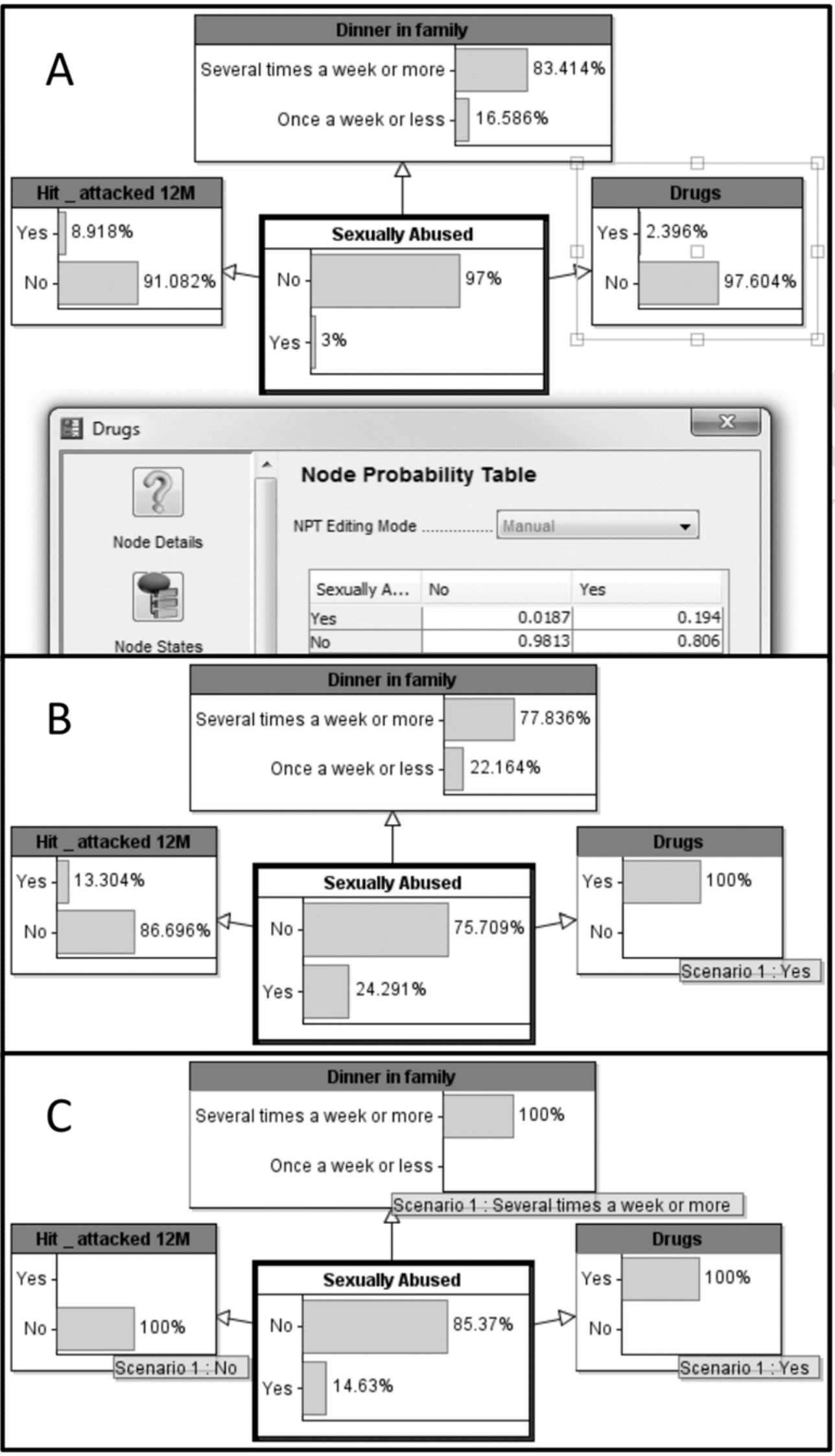

Figure 2. Example of a simple Bayesian classifier in AgenaRisk. 


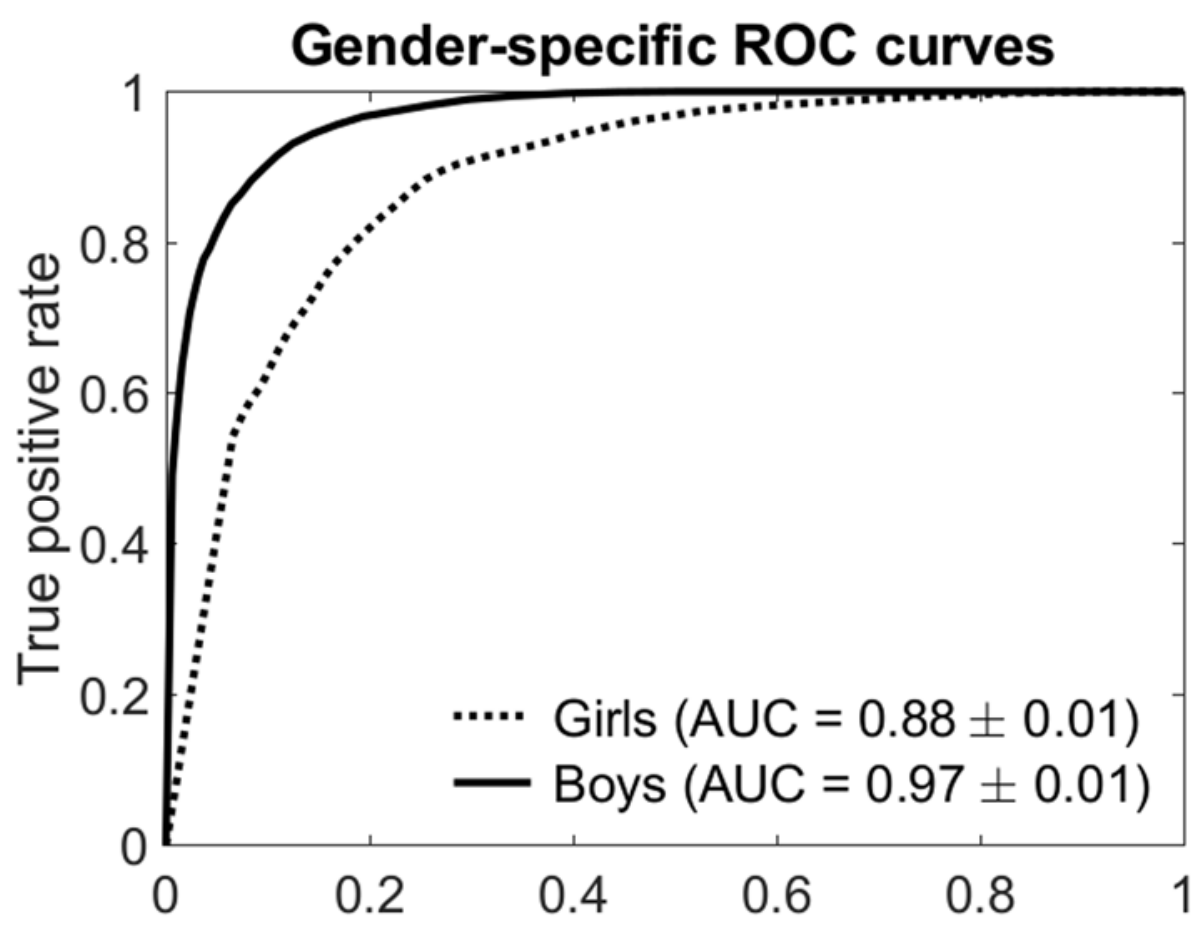

620

False positive rate

621 Figure 3. ROC curves and Area Under the Curve values (mean \pm standard deviation). 


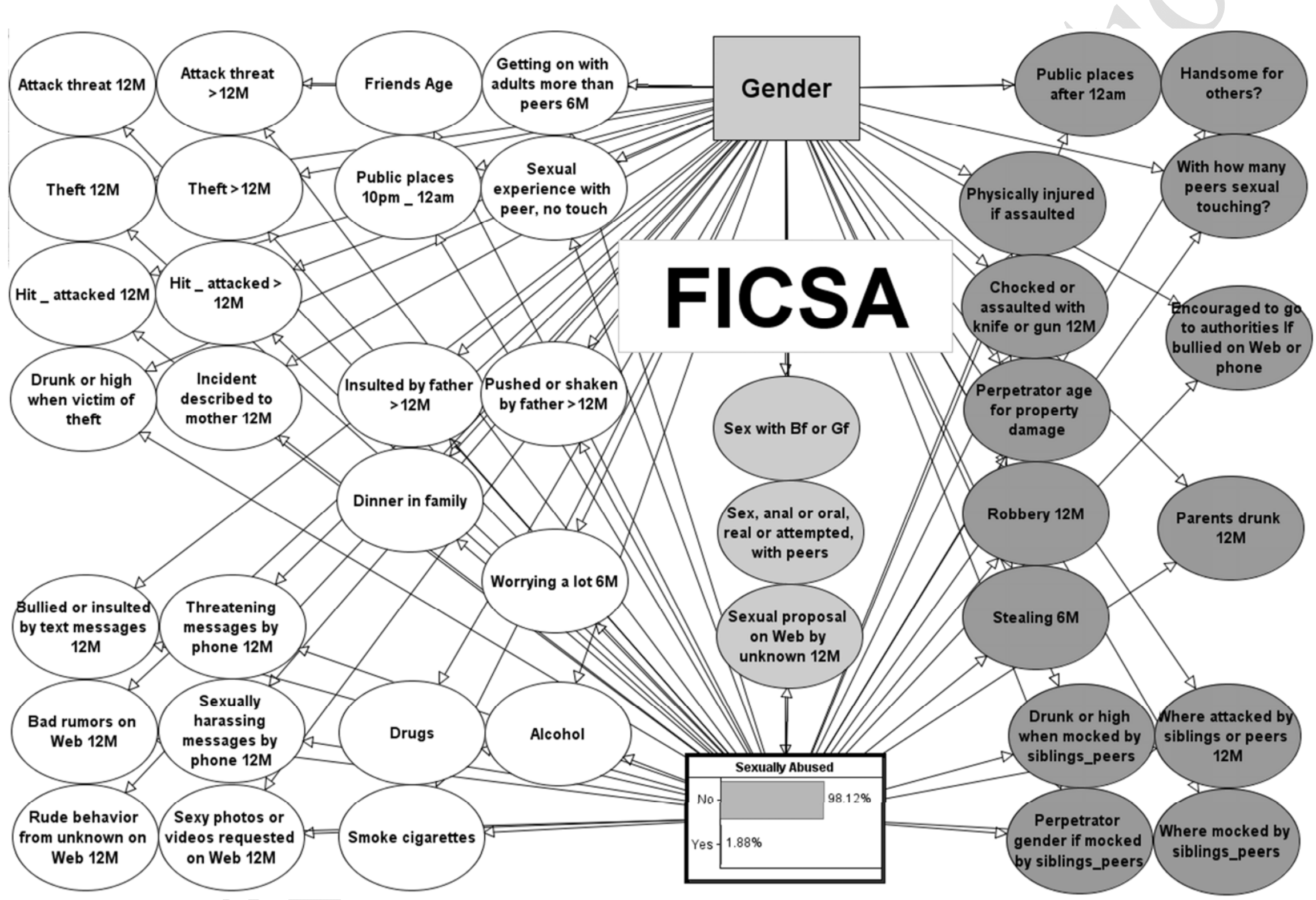

Figure 4. FICSA: A Bayesian network classifier for estimating the probabilty of Child Sexual Abuse. 
Appendix

List of Significant Predictors of CSA. The Bayes factor value measures the marginal dependence between the feature and class variable. The features are ordered in the same order in which they were selected by the feature selection method.

\begin{tabular}{lll}
\hline Feature name & Original question translated in English & Bayes \\
& Factor
\end{tabular}

Valid for girls

Alcohol

Friends Age

Sexually harassing messages

by phone $12 \mathrm{M}$

Sexy photos or videos requested on Web 12M

Public places 10pm _ 12am

Attack threat 12M

Sex, anal or oral, real or attempted, with peers

Drugs

Rude behavior from unknown on Web $12 \mathrm{M}$

Smoke cigarettes

Attack threat $>12 \mathrm{M}$

Bad rumors on Web $12 \mathrm{M}$
Have you ever consumed alcohol, for example half a bottle of beer, a glass of wine or a glass of spirits?

Are the friends you spend most time with...

Have you experienced any of the following in the past 12 months: Someone has sent you sexually harassing messages by phone

Have you experienced any of the following in the past 12 months: Has an unknown person asked you to send sexy photos or videos of yourself to him/her on the Internet?

At what hours do you spend time in these public spaces: Between 10 p.m. and midnight

In addition to incidents you have possibly mentioned above, has anyone only threatened to hit you or attack you in the past 12 months?

Sexual activity, intercourse with a peer - Have you ever had, or have any people of your age attempted to have intercourse or anal or oral sex with you?

Have you ever tried drugs (e.g. hashish or ecstasy)?

Have you experienced any of the following in the past 12 months: Has an unknown person behaved rudely towards you or used obscene language when you have talked to him/her on the Internet?

Do you smoke cigarettes?

Has anyone only threatened you with violence before this?

Have you experienced any of the following in the past 12 months: Someone has spread rumours or written bad things about you on the Internet 


\begin{tabular}{|c|c|c|}
\hline Theft $>12 \mathrm{M}$ & Has anyone stolen something from you without using force before this? & 22.52 \\
\hline Hit_attacked $12 \mathrm{M}$ & $\begin{array}{l}\text { Has anyone hit you or attacked you in the past } 12 \text { months? Here you can also mention offenses that occurred } \\
\text { during violent robberies. }\end{array}$ & 24.32 \\
\hline Hit_attacked $>12 \mathrm{M}$ & Has anyone hit you or attacked you before this? & 26.85 \\
\hline Dinner in family & How often do you eat with one or both of your parents (or those adults who you live with) in the evening? & 26.83 \\
\hline $\begin{array}{l}\text { Sexual proposal on Web by } \\
\text { unknown } 12 \mathrm{M}\end{array}$ & $\begin{array}{l}\text { Have you experienced any of the following in the past } 12 \text { months: Has an unknown person sexually } \\
\text { propositioned you on the Internet? }\end{array}$ & 51.26 \\
\hline Worrying a lot $6 \mathrm{M}$ & If you think about the past 6 months, how do the following apply to you: I worry a lot & 21.47 \\
\hline Insulted by father $>12 \mathrm{M}$ & $\begin{array}{l}\text { When you had rows with your father, did he: Mock you, call you names, swear or otherwise hurt you } \\
\text { emotionally but did not physically hurt you? }\end{array}$ & 21.02 \\
\hline $\begin{array}{l}\text { Incident described to mother } \\
12 \mathrm{M}\end{array}$ & Have you told someone about the most serious incident in the past 12 months: Mother & 21.27 \\
\hline $\begin{array}{l}\text { Sexual experience with peer, } \\
\text { no touch }\end{array}$ & $\begin{array}{l}\text { Sexual experiences with a peer - Have you ever experienced sexual things that did not involve actual physical } \\
\text { touch with someone your age? }\end{array}$ & 18.61 \\
\hline Sex with Bf or Gf & Sexual experiences with a peer - Have you ever had sex with your boyfriend or girlfriend? & 14.82 \\
\hline $\begin{array}{l}\text { Getting on with adults more } \\
\text { than peers } 6 \mathrm{M}\end{array}$ & $\begin{array}{l}\text { If you think about the past } 6 \text { months, how do the following apply to you: I get on better with adults than with } \\
\text { people my own age }\end{array}$ & 19.34 \\
\hline $\begin{array}{l}\text { Bullied or insulted by text } \\
\text { messages } 12 \mathrm{M}\end{array}$ & $\begin{array}{l}\text { Have you experienced any of the following in the past } 12 \text { months: Someone has bullied you or called you } \\
\text { names by text messages }\end{array}$ & 18.18 \\
\hline Theft $12 \mathrm{M}$ & Has anyone stolen something from you without using force in the past 12 months? & 21.67 \\
\hline $\begin{array}{l}\text { Drunk or high when victim of } \\
\text { theft }\end{array}$ & $\begin{array}{l}\text { Theft - Were you under the influence of alcohol or other substances? Depending on "Has anyone ever stolen } \\
\text { something from you without using force? }\end{array}$ & 19.20 \\
\hline $\begin{array}{l}\text { Pushed or shaken by father } \\
>12 \mathrm{M}\end{array}$ & When you had rows with your father, did he: Push, shove or shake you violently? & 13.36 \\
\hline $\begin{array}{l}\text { Threatening messages by } \\
\text { phone } 12 \mathrm{M}\end{array}$ & $\begin{array}{l}\text { Have you experienced any of the following in the past } 12 \text { months: Someone has sent you threatening } \\
\text { messages by phone }\end{array}$ & 18.82 \\
\hline Valid for boys & & \\
\hline
\end{tabular}


Public places after $12 \mathrm{am}$ Sex, anal or oral, real or attempted, with peers

Stealing 6M

With how many peers sexual touching?

Perpetrator age for property damage

Encouraged to go to authorities If bullied on Web or phone

Chocked or assaulted with knife or gun $12 \mathrm{M}$

Robbery $12 \mathrm{M}$

Sexual proposal on Web by unknown $12 \mathrm{M}$

Parents drunk $12 \mathrm{M}$

Handsome for others?

\section{Sex with Bf or Gf}

Drunk or high when mocked by siblings_peers

Perpetrator gender if mocked by siblings_peers
At what hours do you spend time in these public spaces: After midnight

Sexual activity, intercourse with a peer - Have you ever had, or have any people of your age attempted to have intercourse or anal or oral sex with you?

If you think about the past 6 months, how do the following apply to you: I take things that are not mine from home, school or elsewhere

Sexual touching with a peer - With how many people have you had experiences like this? Depending on

"Have you ever experienced sexual touching with someone your age?"

Property damage - How old was the perpetrator? Depending on "Has anyone ever broken or ruined any of your things on purpose?"

Harassment on the Internet or by phone - How did the person(s) you told react or what did they do:

Encouraged me to seek help from authorities

Battery/assault - What kind of violence was used: You were choked or assaulted with a knife or gun. Depending on "Has anyone ever hit you or attacked you?

Has anyone used force to steal something from you in the past 12 months?

Have you experienced any of the following in the past 12 months: Has an unknown person sexually propositioned you on the Internet?

How often in the past 12 months have you seen your parents visibly drunk?

How well do the following apply to your experiences relating to your appearance: I often hear that I am beautiful or handsome

Sexual experiences with a peer - Have you ever had sex with your boyfriend or girlfriend?

Mocking by siblings/peers - Were you under the influence of alcohol or other substances? Depending on

"Has your sister, brother, or a peer ever called you names, said mean things to you, or said that they didn't want you around, which scared you or made you feel really bad?"

Mocking by siblings/peers - Was the perpetrator a girl or a boy? Depending on "Has your sister, brother, or a

peer ever called you names, said mean things to you, or said that they didn't want you around, which scared you or made you feel really bad?"
24.92 
Physically injured if assaulted Battery/assault - Were you hurt, were you physically injured? Depending on "Has anyone ever hit you or attacked you?

Where attacked by siblings or peers $12 \mathrm{M}$

Where mocked by siblings_peers
Peer/sibling violence - Where were you hit or attacked by your sister, brother or a peer? Depending on "Has your sister, brother or a peer ever hit you?"

Mocking by siblings/peers - Where did the mocking take place? Depending on "Has your sister, brother, or a peer ever called you names, said mean things to you, or said that they didn't want you around, which scared you or made you feel really bad?"
9.69 